05,12

\title{
Исследование Sr-допированных ферроманганитов иттербия методами ЭПР и мессбауэровской спектроскопии
}

\author{
(C) И.И. Нигьматуллина ${ }^{1}$, В.В. Парфенов ${ }^{1}$, Р.М. Еремина ${ }^{1,2, \uparrow, ~ Т . П . ~ Г а в р и л о в а ~}{ }^{1,2}$, И.В. Яцык ${ }^{1,2}$ \\ ${ }^{1}$ Казанский (Приволжский) федеральный университет, \\ Казань, Россия \\ ${ }^{2}$ Казанский фризико-технический институт им. Е.К. Завойского ФИЦ КазНЦ РАН, \\ Казань, Россия \\ IE-mail: REremina@yandex.ru \\ (Поступила в Редакцию 20 ноября 2017 г.)
}

\begin{abstract}
Проведены исследования кристаллической структуры стронцийзамещенных манганита и ферроманганитов иттербия $\mathrm{Yb}_{0.82} \mathrm{Sr}_{0.18} \mathrm{Mn}_{1-x} \mathrm{Fe}_{x} \mathrm{O}_{3}(x=0-0.2)$ методами рентгеноструктурного анализа, а также магнитной микроструктуры методами электронного парамагнитного резонанса и ядерной гамма-резонансной (мёссбауэровской) спектроскопии. Установлено, что в керамике наблюдается фазовое расслоение на антиферромагнитную, суперпарамагнитную и ферромагнитную фазы.
\end{abstract}

Работа выполнена при поддержке программы президиума РАН № 5 „Электронный спиновой резонанс, спин-зависящие электронные эффекты и спиновые технологии“.

DOI: $10.21883 /$ FTT.2018.05.45789.333

\section{1. Введение}

Замещение двухвалентным элементом трехвалентного лантаноида в манганитах редкоземельных элементов (Р3Э) приводит к расщеплению магнитной подсистемы образцов на ферро- и антиферромагнитную составляющие. Магнитно-неоднофазное состояние в твердых растворах $R_{1-y} \mathrm{~A}_{y} \mathrm{MnO}_{3}$, где $R-$ редкоземельный катион, А - двухвалентный катион, возникает в этих соединениях вследствие фрустрации магнитных моментов, вызванной конкуренцией ферромагнитного и антиферромагнитного взаимодействий, близких друг к другу по величине. Подавление фрустраций магнитных моментов внешним полем и переход системы в магнитнооднофазное состояние является причиной аномально высоких величин гальвано- и термомагнитных явлений в редкоземельных манганитах [1]. Ферромагнитные кластеры возникают как в антиферромагнитной, так и в парамагнитной матрице. Такое магнитное фазовое расслоение наблюдалось ранее нами в барий-, кальций- и стронцийзамещенных манганитах лантана методом ЭПР $[2,3,4]$, а в ферроманганитах лантана и неодима $\mathrm{Ln}_{1-y} \mathrm{~A}_{y} \mathrm{Mn}_{1-x} \mathrm{Fe}_{x} \mathrm{O}_{3}(\mathrm{~A}=\mathrm{Pb}, \mathrm{Sr} ; \mathrm{Ln}=\mathrm{La}, \mathrm{Nd})$ это расслоение было обнаружено методом мессбауэровской спектроскопии $[5,6]$. Целью данной работы являлось исследование структурных и магнитных свойств мессбауэровских и ЭПР-спектров стронцийзамещенных ферроманганитов иттербия. В отличие от манганитов европия, лантана, неодима, манганиты „тяжелых“ лантаноидов кристаллизуются в ильменито подобной решетке. Замещение в $3 d$-подрешетке части катионов марганца на железо дает возможность исследовать образцы методом мессбауэровской спектроскопии на изотопе ${ }^{57} \mathrm{Fe}$, т.е. получать информацию о типе магнитного упорядочения, дополняющую данные, полученные методом ЭПР.

\section{2. Эксперимент}

Образцы стронцийзамещенных ферроманганитов иттербия были синтезированы по стандартной керамической технологии из взятых в стехиометрическом соотношении смеси исходных оксидов. Шихта обогащалась изотопом ${ }^{57} \mathrm{Fe}$ на $30-50 \%$. Спекание проводилось в три этапа при температурах 1223, 1323 и $1423 \mathrm{~K}$ соответственно по $8 \mathrm{~h}$ каждое с промежуточной помолом керамики. Подробнее синтез образцов описан в [7]. Рентгеноструктурный анализ выполнен на дифрактометре Rigaku Smart Lab на трубке с Cu-анодом в дискретном режиме с шагом $0.04^{\circ}$. Мессбауэровские спектры получены при температурах $T=295, T=170$ и $T=80 \mathrm{~K}$. Параметры спектров рассчитаны с помощью стандартной программы UNIVEM MS. Измерения спектров ЭПР осуществлены на спектрометре Bruker EMX в температурном интервале $100-320 \mathrm{~K}$ на частоте $9.4 \mathrm{GHz}$.

\section{3. Рентгеноструктурный анализ}

По данным рентгеноструктурного анализа (РСА) установлено, что все образцы имеют структуру ильменита (пространственная группа $P 6_{3} \mathrm{~cm}$ ). Дифрактограмма $\mathrm{Yb}_{0.82} \mathrm{Sr}_{0.18} \mathrm{Mn}_{0.85} \mathrm{Fe}_{0.15} \mathrm{O}_{3}$ представлена на рис. 1 , в табл. 1 приведены параметры кристаллической решетки образцов.

Замещение части трехвалентного марганца железом, имеющим меньший ионный радиус, приводит к увеличению параметра $c$, и уменьшению параметра $a$ 


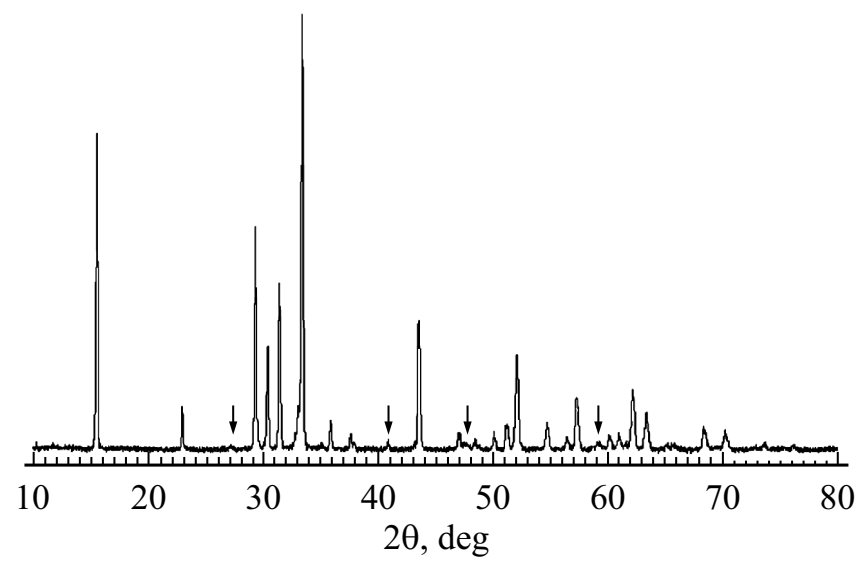

Рис. 1. Дифрактограмма $\mathrm{Yb}_{0.82} \mathrm{Sr}_{0.18} \mathrm{Mn}_{0.85} \mathrm{Fe}_{0.15} \mathrm{O}_{3}$. Стрелками отмечены рефлексы, соответствующие орторомбической фазе $\mathrm{Sr}(\mathrm{Mn}, \mathrm{Fe}) \mathrm{O}_{3}$.

кристаллической решетки. Образцы при этом остаются практически структурно однофазными, хотя незначительные по интенсивности рефлексы, соответствующие орторомбическому $\mathrm{Sr}(\mathrm{Mn}, \mathrm{Fe}) \mathrm{O}_{3}$, в дифрактограммах все же присутствуют (отмечены стрелками на рис. 1). Количественный анализ дифрактограмм позволил установить, что содержание ферроманганита стронция $\mathrm{Sr}(\mathrm{Mn}, \mathrm{Fe}) \mathrm{O}_{3}$ не превышает 5\%.

Манганит стронция $\mathrm{SrMnO}_{3}$ может существовать в двух кристаллических модификациях - орторомбической и гексагональной [8]. В первой марганец и, следовательно, замещающее его железо будут находиться в октаэдрическом окружении с координационным числом
Таблица 1. Параметры кристаллической структуры соединений $\mathrm{Yb}_{0.82} \mathrm{Sr}_{0.18} \mathrm{Mn}_{1-x} \mathrm{Fe}_{x} \mathrm{O}_{3}$

\begin{tabular}{c|c|c}
\hline Соединение & $a, \AA$ & $c, \AA$ \\
\hline $\mathrm{Yb}_{0.82} \mathrm{Sr}_{0.18} \mathrm{Mn}_{0.9} \mathrm{Fe}_{0.1} \mathrm{O}_{3}$ & 6.065 & 11.399 \\
$\mathrm{Yb}_{0.82} \mathrm{Sr}_{0.18} \mathrm{Mn}_{0.85} \mathrm{Fe}_{0.15} \mathrm{O}_{3}$ & 6.060 & 11.413 \\
$\mathrm{Yb}_{0.82} \mathrm{Sr}_{0.18} \mathrm{Mn}_{0.8} \mathrm{Fe}_{0.2} \mathrm{O}_{3}$ & 6.057 & 11.423
\end{tabular}

КЧ-6, во второй - в центре октаэдров, имеющих общие грани и образующих комплексы $\mathrm{Mn}_{2} \mathrm{O}_{9}$ (рис. 2). Методом PCA гексагональный $h$ - $\mathrm{SrMnO}_{3}$ зарегистрировать не удается.

\section{4. Мессбауэровская спектроскопия}

В спектрах ядерного гамма резонанса (ЯГР) ферроманганитов иттербия при комнатной температуре и при $T=170 \mathrm{~K}$ не наблюдается магнитной сверхтонкой структуры. Для $x=0.1$ и $x=0.15$ спектры хорошо описываются суперпозицией двух дублетов (рис. 3) с расщеплениями, соответствующими искаженному октаэдрическому и гексаэдрическому окружению мессбауэровского катиона. Для $x=0.2$ спектры хорошо описываются суперпозицией трех квадрупольных дублетов (рис. 4) с расщеплениями, соответствующими искаженным гексаэдрическому и двум октаэдрическим окружениям мессбауэровского катиона, при этом в одном из октаэдрических окружений мессбауэровский катион смещен из центра октаэдра. Параметры спектров сведены в табл. 2.
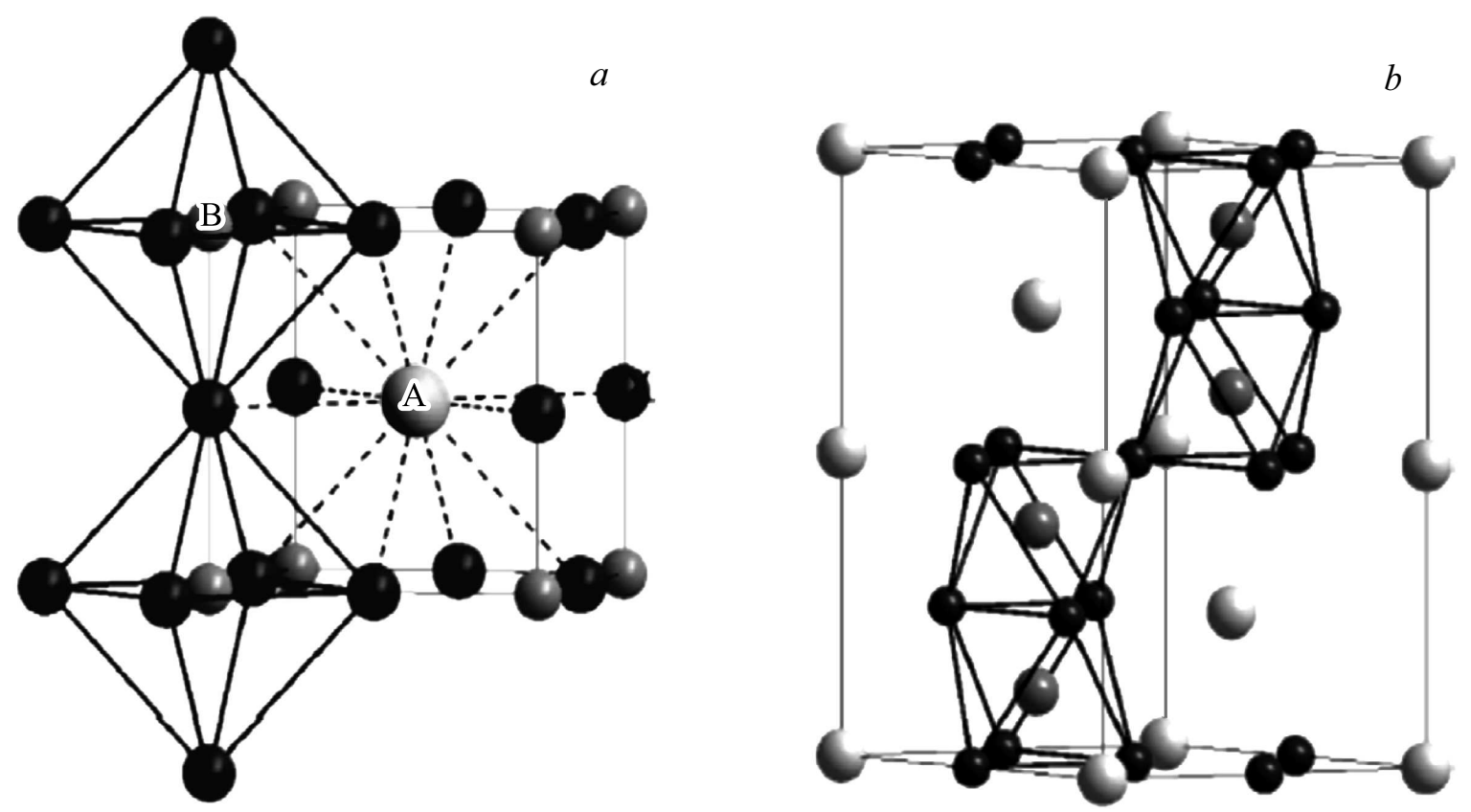

Рис. 2. Структуры орторомбического $(a)$ и гексагонального $(b) \mathrm{SrMnO}_{3}$. Ионы кислорода показаны черными, ионы марганца темно-серыми, ионы стронция/железа - светло серыми сферами. 


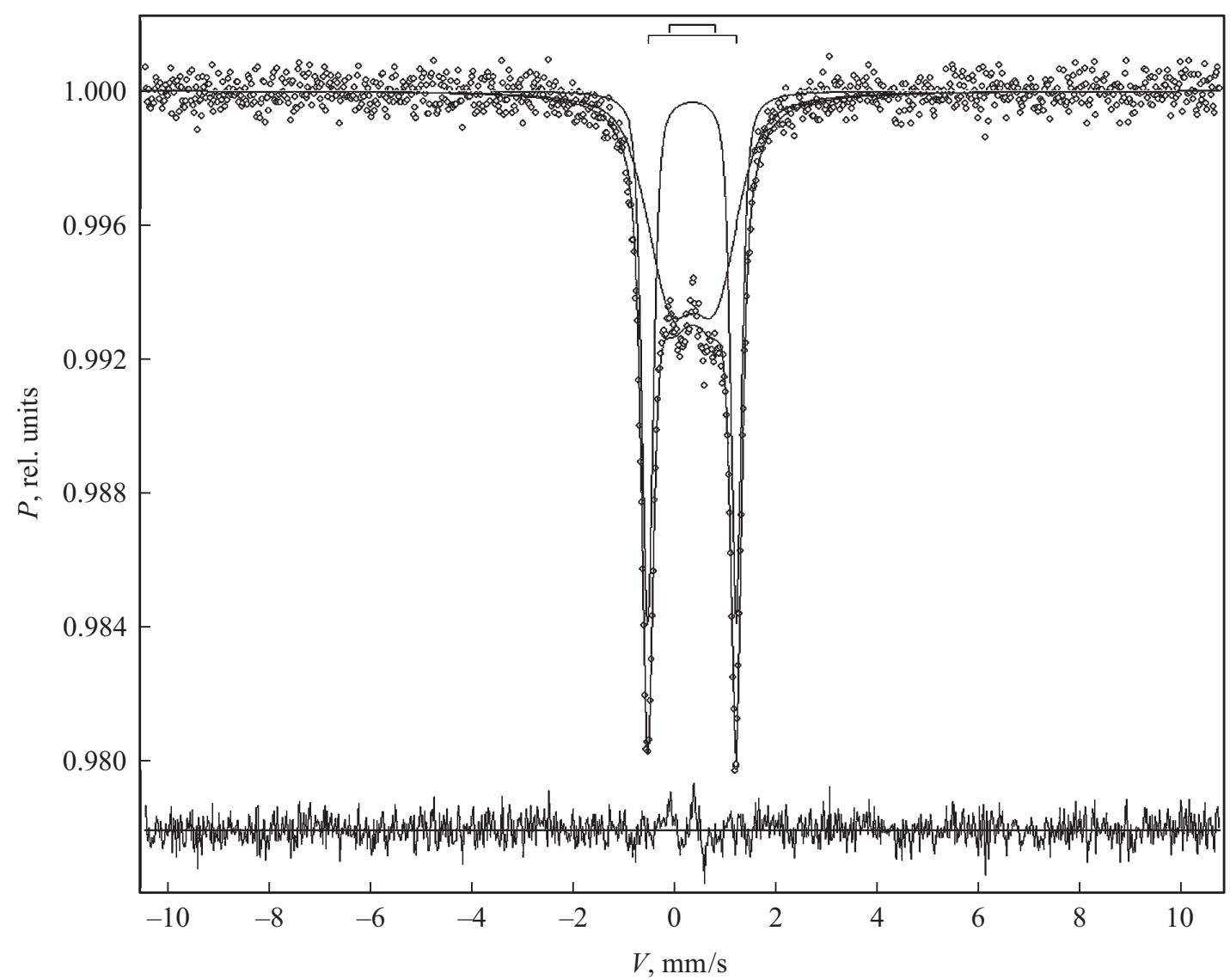

Рис. 3. Мессбауэровский спектр $\mathrm{Yb}_{0.82} \mathrm{Sr}_{0.18} \mathrm{Mn}_{0.9} \mathrm{Fe}_{0.1} \mathrm{O}_{3}(T=295 \mathrm{~K})$.

Гексаэдрическое (бипирамидальное) окружение отвечает размещению железа в позициях марганца в основной фазе $\mathrm{Yb}_{0.82} \mathrm{Sr}_{0.18} \mathrm{Mn}_{1-x} \mathrm{Fe}_{x} \mathrm{O}_{3}$. Для такого окружения (КЧ-5) характерно большое значение квадрупольного расщепления $Q_{S}=1.72 \mathrm{~mm} / \mathrm{s}$. Остальные два дублета с меньшим $Q_{S}$ отвечают искаженному октаэдрическому окружению катиона $\mathrm{Fe}^{3+}$, которое реализуется как в орторомбической, так и в гексагональной фазе $\mathrm{SrMnO}_{3}$.

Низкотемпературные измерения выполнены для образца с $x=0.2$ (рис. 5). При температуре $80 \mathrm{~K}$ в спектре образца появляется магнитная сверхтонкая структура

Таблица 2. Параметры мессбауэровских спектров ферроманганитов иттербия $\mathrm{Yb}_{0.82} \mathrm{Sr}_{0.18} \mathrm{Mn}_{1-x} \mathrm{Fe}_{x} \mathrm{O}_{3}$ при $300 \mathrm{~K}$

\begin{tabular}{c|c|c|c|c|c|c}
\hline $\mathrm{T}, \mathrm{K}$ & $x$ & & $\begin{array}{c}I_{S}, \mathrm{~mm} / \mathrm{s} \\
(0.005)\end{array}$ & $\begin{array}{c}Q_{S}, \mathrm{~mm} / \mathrm{s} \\
(0.005)\end{array}$ & $\begin{array}{c}G, \mathrm{~mm} / \mathrm{s} \\
(0.005)\end{array}$ & $\begin{array}{c}S_{\text {rel }} \\
\%\end{array}$ \\
\hline \multirow{6}{*}{300} & \multirow{2}{*}{0.1} & D1 & 0.325 & 0.624 & 0.661 & 40 \\
& \multirow{2}{*}{0.15} & D2 & 0.299 & 1.735 & 0.291 & 60 \\
\cline { 2 - 7 } & & D2 & 0.321 & 0.651 & 0.62 & 38.5 \\
\cline { 2 - 7 } & \multirow{3}{*}{0.2} & D1 & 0.297 & 1.759 & 0.311 & 61.5 \\
\hline & & D2 & 0.321 & 0.403 & 0.301 & 8.4 \\
& & D3 & 0.301 & 0.91 & 0.57 & 28.5
\end{tabular}

с эффективным полем $H_{\mathrm{eff}}=354 \mathrm{kOe}$ и квадрупольным расщеплением $Q_{S}=0.79 \mathrm{~mm} / \mathrm{s}$. Вместе с тем в спектре образца остается дублет с $Q_{S}=1.49 \mathrm{~mm} / \mathrm{s}$.

Отметим, что обработку этого спектра с помощью программы UnivemMS нельзя признать вполне удовлетворительной, т.к. 3 и 4 линии секстета получаются неоправданно большой ширины. Причиной может выступать появление магнитной сверхтонкой структуры, отвечающей орторомбической и гексагональной фазам $\mathrm{SrMnO}_{3}$, но при достигнутой точности эксперимента уверенно выделить эти вклады не удалось.

\section{5. ЭПР-спектроскопия}

Во всем температурном интервале формы линий спектра ЭПР описывались выражением следующего вида [9]:

$$
Y(H) \propto \frac{d}{d H}\left[\frac{\Delta H+\alpha\left(H-H_{0}\right)}{\Delta H^{2}+\left(H-H_{0}\right)^{2}}+\frac{\Delta H-\alpha\left(H+H_{0}\right)}{\Delta H^{2}+\left(H+H_{0}\right)^{2}}\right] .
$$

Выражение (1) соответствует асимметричной линии лоренцевой формы, которая включает в себя сигналы как поглощения, так и дисперсии, при этом параметр $\alpha$ обозначает отношение доли дисперсии к доли абсорбции. Поскольку в исследуемых соединениях ширина 


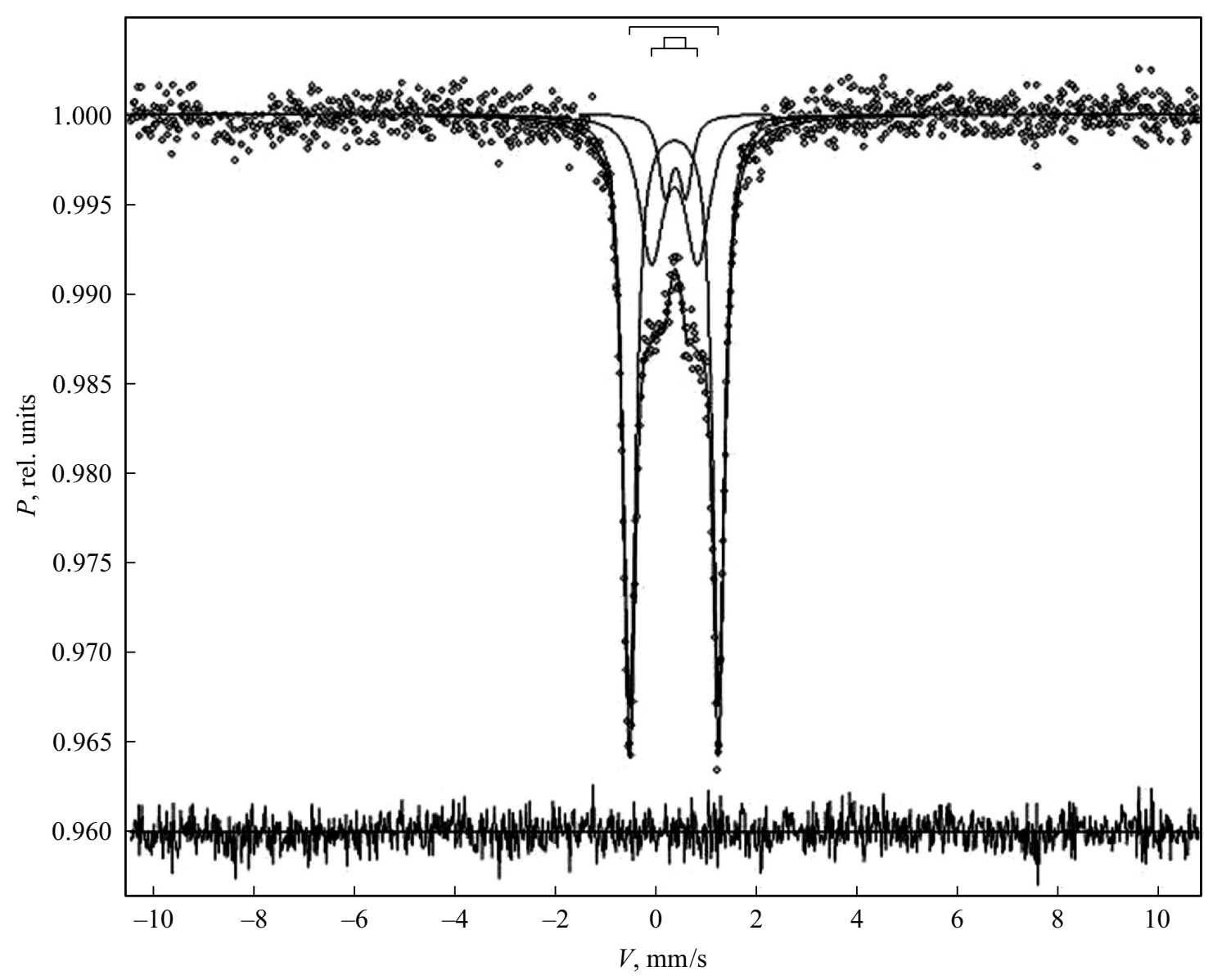

Рис. 4. Мессбауэровский спектр $\mathrm{Yb}_{0.82} \mathrm{Sr}_{0.18} \mathrm{Mn}_{0.8} \mathrm{Fe}_{0.2} \mathrm{O}_{3}(T=295 \mathrm{~K})$.

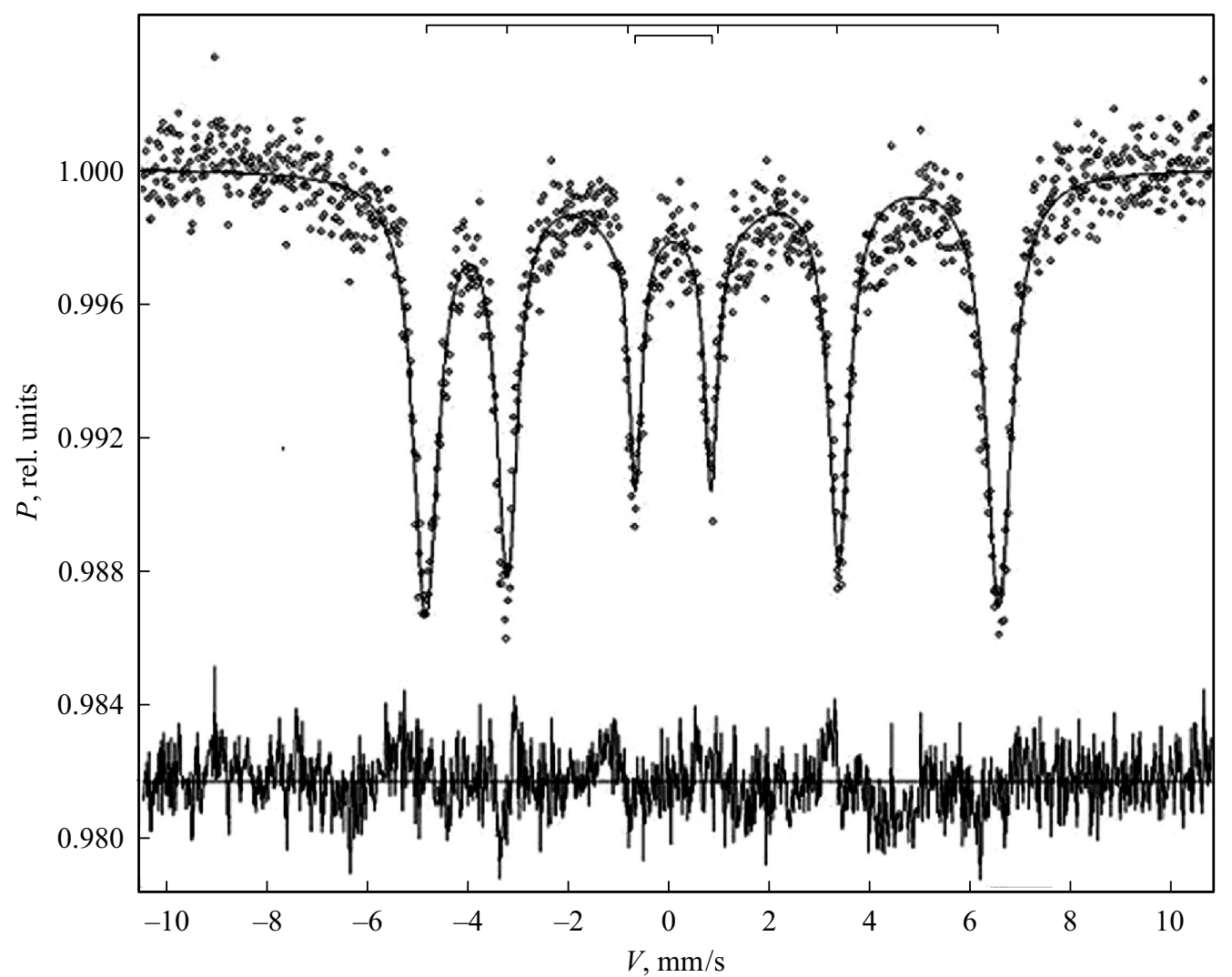

Рис. 5. Мессбауэровский спектр $\mathrm{Yb}_{0.82} \mathrm{Sr}_{0.18} \mathrm{Mn}_{0.8} \mathrm{Fe}_{0.2} \mathrm{O}_{3}(T=80 \mathrm{~K})$. 

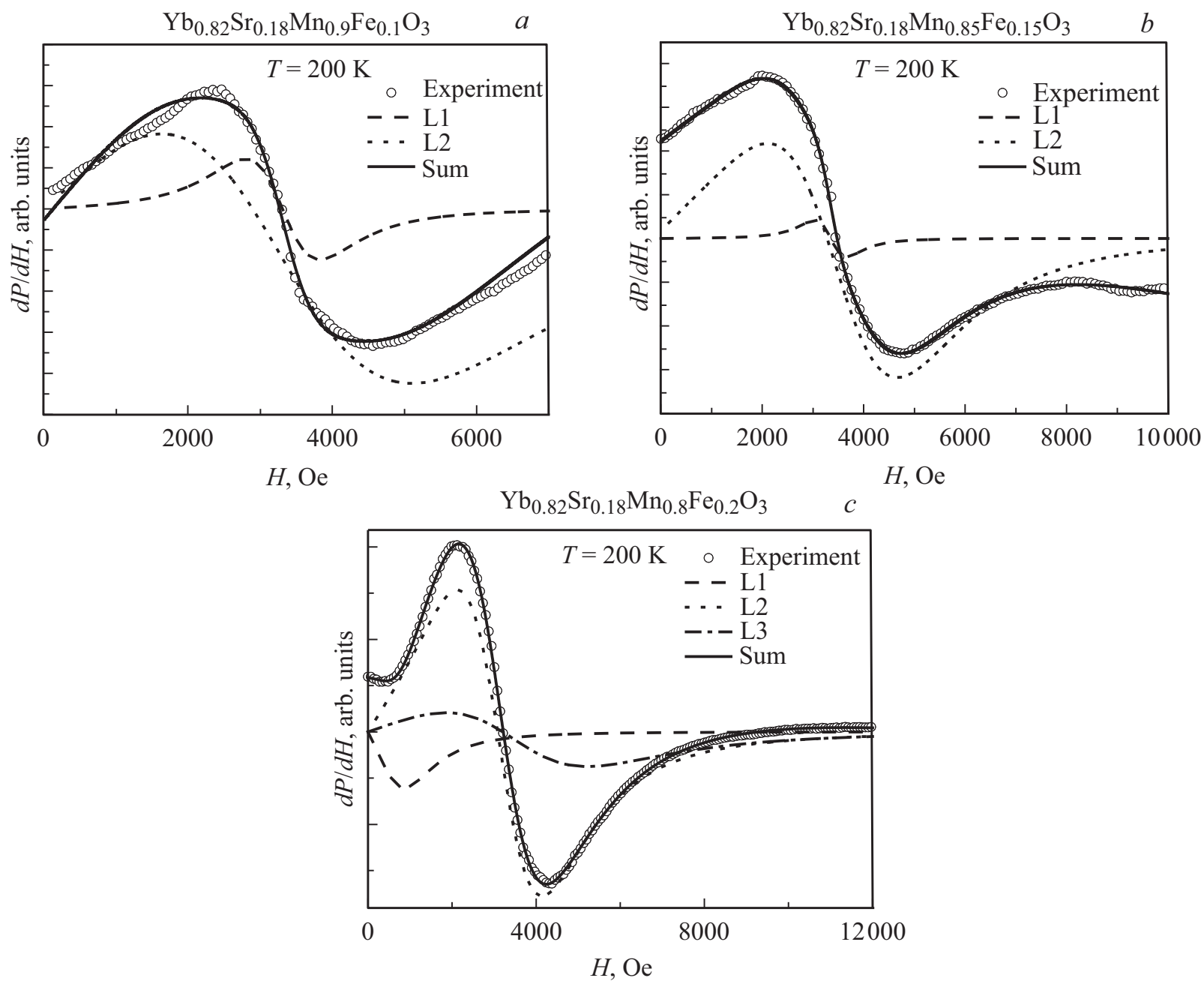

Рис. 6. Вид спектра ЭПР в $\mathrm{Yb}_{0.82} \mathrm{Sr}_{0.18} \mathrm{Mn}_{1-x} \mathrm{Fe}_{x} \mathrm{O}_{3}$ при температуре $T=200 \mathrm{~K}$ для $(a) x=0.1 ;(b) x=0.15$; $(c) x=0.2$. Символы - экспериментальные данные, линии - теоретический расчет.

линии сигнала ЭПР $\Delta H$ имеет значения одного порядка с величиной резонансного поля $H_{0}$, необходимо принимать во внимание обе циркулярные компоненты возбуждающего линейно поляризованного микроволнового поля, таким образом, выражение (1) включает в себя резонансное поле как со знаком плюс $+H_{0}$, так и со знаком минус $-\mathrm{H}_{0}$.

Спектры ЭПР для образцов $\mathrm{Yb}_{0.82} \mathrm{Sr}_{0.18} \mathrm{Mn}_{1-x} \mathrm{Fe}_{x} \mathrm{O}_{3}$ $(x=0.1,0.15)$ представляли из себя сумму двух линий лоренцевой формы, задаваемой выражением (1), при этом спектр ЭПР-образцов с высокой концентрацией железа $\mathrm{Yb}_{0.82} \mathrm{Sr}_{0.18} \mathrm{Mn}_{0.8} \mathrm{Fe}_{0.2} \mathrm{O}_{3}$ представлял из себя сумму трех линий. Следует отметить, что для каждого образца количество линий, использованных для описания спектров ЭПР, совпадает с количеством дублетов, использованных для описания мессбауэровских спектров. Вид экспериментально полученных спектров ЭПР в керамиках $\mathrm{Yb}_{0.82} \mathrm{Sr}_{0.18} \mathrm{Mn}_{1-x} \mathrm{Fe}_{x} \mathrm{O}_{3}$ и их теоретического описания приведен на рис. 6.

Из анализа спектров ЭПР керамических образцов $\mathrm{Yb}_{0.82} \mathrm{Sr}_{0.18} \mathrm{Mn}_{1-x} \mathrm{Fe}_{x} \mathrm{O}_{3} \quad(x=0.1,0.15,0.2)$ полу- чены температурные зависимости $g$-факторов, ширин и интенсивностей линий ЭПР, которые представлены на рис. 7, $a, b$ и $c$ соответственно. Как было отмечено выше, описание спектров ЭПР в керамике $\mathrm{Yb}_{0.82} \mathrm{Sr}_{0.18} \mathrm{Mn}_{0.9} \mathrm{Fe}_{0.1} \mathrm{O}_{3}$ проводилось с использованием двух линий $\mathrm{L} 1(0.1)$ и $\mathrm{L} 2(0.1)$. Значения $g$-факторов этих линий при комнатной температуре совпадают и равны 1.963. Данное значение эффективного $g$-фактора характерно для линии от обменно-связанных спинов ионов марганца $\mathrm{Mn}^{3+}[2,3,4]$. При понижении температуры величины эффективного $g$-фактора увеличиваются незначительно для L 1(0.1) и L2(0.1), что говорит о том, что внутренние локальные магнитные поля компенсируют друг друга. При этом линии L1(0.1) и $\mathrm{L} 2(0.1)$ имеют разную ширину и интенсивность. Ширина линии L1(0.1) при понижении температуры от комнатной до $150 \mathrm{~K}$ возрастает примерно в 2.5 раза от 2000 до 4500 Ое. Ниже температуры $150 \mathrm{~K}$ сигнал магнитного резонанса зарегистрировать не удалось из-за сильного уширения линии $\mathrm{L} 1(0.1)$ при приближении к температуре антиферромагнитного упорядочения. Ширина 

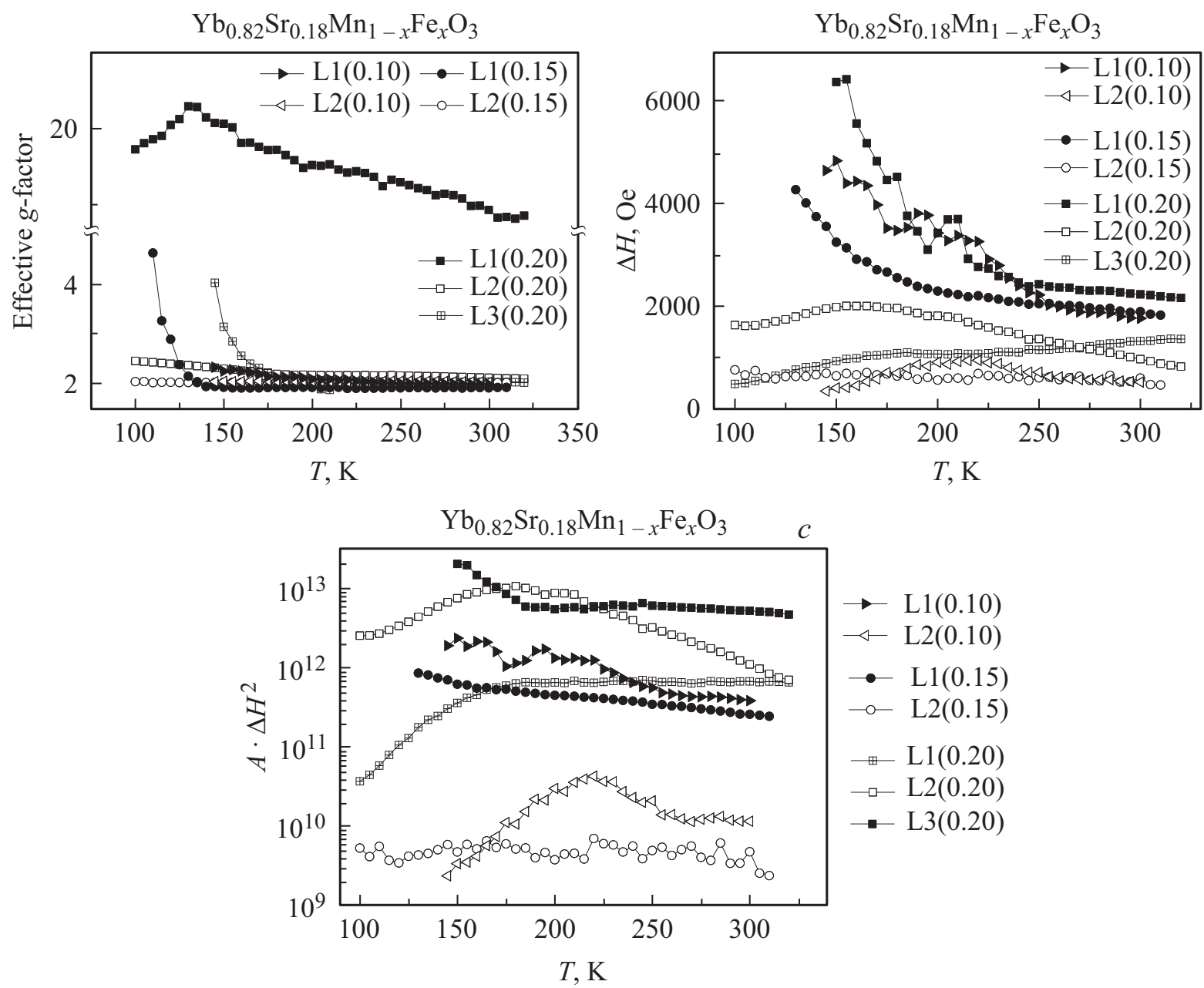

Рис. 7. Температурные зависимости (a) g-фактора; (b) ширины; (c) интенсивности линии ЭПР в $\mathrm{Yb}_{0.82} \mathrm{Sr}_{0.18} \mathrm{Mn}_{1-x} \mathrm{Fe}_{x} \mathrm{O}_{3}(x=0.1$, $0.15,0.2)$.

линии L2(0.1) практически не меняется и составляет порядка 1000 Ое, ее интенсивность проходит через максимум при $218 \mathrm{~K}$ и убывает при понижении температуры. Мы связываем этот сигнал с суперпарамагнитной фазой образца.

Сигнал магнитного резонанса для керамики $\mathrm{Yb}_{0.82} \mathrm{Sr}_{0.18} \mathrm{Mn}_{1-x} \mathrm{Fe}_{x} \mathrm{O}_{3}(x=0.15)$ также аппроксимировался суммой двух линий L1(0.15) и L2(0.15), которые имеют ту же природу, что и для предыдущего образца $\mathrm{Yb}_{0.82} \mathrm{Sr}_{0.18} \mathrm{Mn}_{1-x} \mathrm{Fe}_{x} \mathrm{O}_{3} \quad(x=0.1)$. То есть, линия L1(0.15) относится к фазе образца, в которой наблюдается антиферромагнитное упорядочение. Интенсивность, положение и ширина линии L2(0.15) практически не меняются с температурой в изучаемом температурном диапазоне, что свидетельствует о суперпарамагнитной природе данного сигнала.

Описание спектров ЭПР в керамике $\mathrm{Yb}_{0.82} \mathrm{Sr}_{0.18} \mathrm{Mn}_{1-x} \mathrm{Fe}_{x} \mathrm{O}_{3}(x=0.2)$ проводилось с использованием трех линий лоренцевой формы, описываемой выражением (1). Температурное поведение параметров двух линий L1(0.2) и L2(0.2) аналогично поведению со- ответствующих линий в образцах с $x=0.1$ и 0.15 . Ниже $200 \mathrm{~K} \cdot \mathrm{g}$ - фактор и ширина линии L1(0.2) возрастает, что говорит о значительном влиянии внутренних локальных магнитных полей. Мы предполагаем, что линия L1(0.2) относится к фазе образца, в которой наблюдается антиферромагнитное упорядочение. Ширина линии ЭПР L2(0.2) меняется в диапазоне от 1000 до 2000 Oе, что сравнимо с величиной, полученной для манганитов с гексагональной и орторомбической структурой, в частности, для $\mathrm{YbMnO}_{3}$ или $\mathrm{GdMnO}_{3}[10,11]$. Интенсивность линии ЭПР L2(0.2) проходит через максимум при $180 \mathrm{~K}$ и убывает при понижении температуры, что свидетельствует о ее суперпарамагнитной природе. Линия L3(0.2) имеет ферромагнитную природу с эффективным $g$-фактором, меняющимся в пределах от 20 до 14. Как видно на рис. $6, b$, в спектре магнитного резонанса наблюдается только часть линии L3(0.2), поэтому ошибка определения положения, ширины и интегральной интенсивности L 3(0.2) составляет порядка 50\%.

Наблюдение нескольких линий разной природы: антиферромагнитной, суперпарамагнитной и ферромагнит- 
ной в спектре ЭПР ферроманганитов иттербия говорит о сильном фазовом расслоении в изучаемых керамиках.

\section{6. Выводы}

Из исследований стронцийзамещенных ферроманганитов иттербия $\mathrm{Yb}_{0.82} \mathrm{Sr}_{0.18} \mathrm{Mn}_{1-x} \mathrm{Fe}_{x} \mathrm{O}_{3}(x=0.1 ; 0.15 ; 0.2)$ методами рентгеноструктурного анализа, электронного парамагнитного резонанса и мёссбауэрской спектроскопии можно сделать следующие выводы:

1. Все образцы имеют структуру ильменита с пространственной группой $P 6_{3} \mathrm{~cm}$. Кристаллографический параметр $c$ увеличивается, а параметр $a$ уменьшается с увеличением концентрации ионов железа.

2. В температурном диапазоне от 120 до $320 \mathrm{~K}$ все исследуемые образцы находятся в парамагнитном состоянии.

3. По данным мессбауэровской спектроскопии электронное фазовое расслоение наблюдается в исследуемых образцах при температурах ниже $80 \mathrm{~K}$.

4. Спектр ЭПР исследуемых образцов состоит из двух линий в температурном диапазоне от 120 до $320 \mathrm{~K}$ для $x=0.1,0.15$ и трех линий для $x=0.2$. Наблюдение нескольких линий в спектре ЭПР обусловлено фазовым расслоением и наличием в образце антиферромагнитных, суперпарамагнитных и ферромагнитных областей.

\section{Список литературы}

[1] Э.Л. Нагаев. УФН 166, 833 (1996).

[2] R.M. Eremina, I.V. Yatsyk, Ya.M. Mukovski, H.-A. Krugvon Nidda, A. Loidl. JETP Lett. 85, 51 (2007).

[3] I.V. Yatsyk, R.M. Eremina, M.M. Shakirzyanov, Ya.M. Mukovskii, H.-A. Krugvon Nidda, A. Loidl. JETP. Lett. 87, 447 (2008).

[4] J. Deisenhofer, D. Braak, H.-A. Krug von Nidda, J. Hemberger, R.M. Eremina, V.A. Ivanshin, A.M. Balbashov, G. Jug, A. Loidl, T. Kimura, Y. Tokura. Phys. Rev. Lett. 95, 257202 (2005).

[5] В.В. Парфенов, Ш.Ш. Башкиров, А.А. Валиуллин, А.В. Аверьянов. ФТТ 42, 1272 (2000).

[6] I.A. Abdel-Latif, A.S. Khramov, V.A. Trounov, O.P. Smirnov, Sh.Sh. Bashkirov, V.V. Parfenov, E.A. Tserkovnaya, G.G. Gumarov, Sh.Z. Ibragimov. Egyp. J. Solids 19, 341 (2006).

[7] Sh.Sh. Bashkirov, N.V. Boltakova, V.V. Parfenov, R.A. Nazipov, A.V. Pyataev, I.A. Gabidullin. Bull. Russ. Acad. Sci.: Physics 74, 343 (2010).

[8] R. Søndenå, P. Ravindran, S. Stølen, T. Grande, M. Hanfland. Phys. Rev. B 74, 144102 (2006).

[9] P.J. Janhavi, S.V. Bhat. J. Magn. Res. 168, 284 (2004).

[10] R.M. Eremina, T.P. Gavrilova, I.V. Yatsyk, R.B. Zaripov, A.A. Sukhanov, V.A. Shustov, N.M. Lyadov, V.I. Chichkov, N.V. Andreev. Appl. Magn. Res. 47, 869 (2016).

[11] I.V. Yatsyk, D.V. Mamedov, I.I. Fazlizhanov, T.P. Gavrilova, R.M. Eremina, N.V. Andreev, V.I. Chichkov, Ya.M. Mukovskii, H.-A. Krug von Nidda, A. Loidl. JETP Lett. 96, 416 (2012). 